ISSN: 0213-2079 - ISSN electrónico: 2386-3889

DOI: https://doi.org/10.14201/shhmo2019412339367

\title{
EL QUID DE LA CUESTIÓN. SOBRE SENTENCIAS DE VISITA Y SU EJECUCIÓN: EL CASO DE LA VISITA DEL GENERAL DE CATALUNYA, 1599-1711
}

\section{Monarchy control instruments over the Generalitat of Catalonia}

\author{
Ricard TORRA-PRAT ${ }^{1}$ \\ Ludwig-Maximilians-Universität München \\ Correo-e: ricard.torra.prat@gmail.com
}

Fecha de recepción: 15 de octubre de 2018

Fecha de aceptación: 4 de agosto de 2019

RESUMEN: A lo largo de las últimas décadas, el estudio de los sistemas de fiscalización presentes en el espacio político de la Monarquía Hispánica de los Austrias ha gozado de una notable producción. En este sentido, Visitas, Juicios de Residencia y Pesquisas han sido estudiadas profusamente, lo que nos ha llevado a comprender mucho mejor tanto su funcionamiento, como sus virtudes y puntos débiles. No obstante, aunque una parte nada desdeñable de dichos estudios ha apuntado a la aparente «inutilidad» de estos sistemas, ninguno ha emprendido un estudio sistemático de las sentencias por ellos promulgadas. El objetivo de este artículo es el análisis de las sentencias de la Visita del General de Catalunya y su mecanismo de ejecución.

Palabras clave: Visita del General; Fiscalización; Historia institucional; Monarquía Hispánica; Siglo XVII.

1. Alexander von Humboldt Fellow. Este estudio se desarrolló dentro de las actividades del proyecto de investigación: «Manuscrits. Grup de Recerca d'Història Moderna. Identitats, cultura i pensament polític en el procés de construcció nacional català (2017 SGR 949)».

Ediciones Universidad de Salamanca / అ@@ Stud. his., H. ${ }^{a}$ mod., 41, n. 2 (2019), pp. 339-367 
ABSTRACT: Within the last decades, there has been a noticeable increase regarding the study of the accountability institutions of the territories of the Early Modern Spanish Monarchy. Thus, it allowed improving our knowledge concerning Visitas, Juicios de Residencia and Pesquisas' procedures, virtues and weak points. However, although the previous literature has argued that these institutions were to some extent futile, none of these works has studied systematically their sentences. The main objective of this paper is to analyse the sentences of the Visita of the Generality of Catalonia and its execution procedure.

Keywords: Visita del General; accountability; institutional history; Spanish Monarchy; 17th Century.

\section{INTRODUCCIÓN}

A lo largo de los últimos decenios, los sistemas de fiscalización de los oficiales públicos de las instituciones de la Monarquía Hispánica vienen siendo estudiados por numerosos especialistas. Así, Visitas Generales, Juicios de Residencia y Pesquisas han sido examinados desde enfoques metodológicos y campos de conocimiento harto distantes entre sí (Macri, 2008: 385-400). Sin embargo la mayoría de estas obras se han caracterizado, bien por centrarse en el análisis procedimental de dichos sistemas fiscalizadores (González Alonso, 1978: 193-247; Garriga Acosta, 1991: 215-390; Collantes de Terán de la Hera, 1998: 151-184), bien en constatar la potencialidad que las visitas tenían como mecanismos que la monarquía usaba para informarse del funcionamiento de la administración de los reinos de la "periferia» (Rivero Rodríguez, 1998: 705-730; Herzog, 2000; Peytavin, 2003) o en último término en investigar las acusaciones elaboradas por los visitadores y jueces de residencia con el objetivo de descubrir en ellas prácticas corruptas desarrolladas por la oficialidad (Gómez González, 2016: 235-249; Malaprade, 2017: 363-387)².

En efecto, cualquiera que repase la producción historiográfica relacionada con el estudio de las instituciones fiscalizadoras en el ámbito político de la Monarquía Hispánica de los Austrias, rápidamente puede constatar que no existe ningún estudio dedicado exclusivamente a pormenorizar la cuestión de las sentencias producidas por dichos organismos. Por el contrario, abundan los juicios de valor un tanto gratuitos acerca de la «inutilidad» de visitas, pesquisas y juicios de residencia. Por ejemplo, hace ya algunos años, en su trabajo sobre los juristas napolitanos del seiscientos, Rovito (Rovito, 1981: 77) aseguró que las visitas «non erano che una

2. Un reciente estado de la cuestión sobre los sistemas de fiscalización en el seno de la Monarquía Hispánica de los Austrias en Andújar Castillo, Feros y Ponce Leiva (2017: 284-311).

Ediciones Universidad de Salamanca / 요 Stud. his., H. ${ }^{a}$ mod., 41, n. 2 (2019), pp. 339-367 
modestissima parodia dell'Inquisición»; en consonancia con el historiador italiano, Herzog (Herzog, 2000: 122) ya afirmó en su día que aunque la Visita general de la Audiencia de Quito de 1691-1692 le había servido a la monarquía para acumular información sobre dicha Audiencia, el gobierno quiteño, los funcionarios regios y el patriciado urbano, «la utilidad de la misma no es evidente»; más aún, recientemente Jiménez Jiménez (Jiménez Jiménez, 2015: 85) ha aseverado que «el estudio de los métodos de control usados por la Monarquía hispánica [sic] desde los inicios de la colonización hasta el relevo de la dinastía Habsburgo por la Borbón, demuestra, bien a las claras, una inutilidad manifiesta».

En contraste con la posición de los investigadores arriba mencionados, hace ya algunos años Sánchez Bella (Sánchez Bella, 1980: 406) destacó el papel positivo de los mecanismos de control de los oficiales regios de la Monarquía Hispánica en América, advirtiendo que «no cabe duda que, de ordinario, el castigo merecido se llevaba a cabo». De manera análoga, Gómez González (Gómez González, 2017: 313-314) ha recalcado la necesidad de obviar enfoques apriorísticos. En este sentido, para Gómez González determinar la eficacia de las visitas sería una tarea harto compleja, puesto que ello sería posible solamente a partir del análisis de casos concretos en los que además del estudio de una determinada inspección, pudiéramos igualmente comprobar el estado de las instituciones visitadas antes y después de la fiscalización. Asimismo, Andújar Castillo, Feros y Ponce Leiva (Andújar Castillo, Feros y Ponce Leiva, 2017: 303-305) han advertido que a pesar de que la documentación producida por los mecanismos de control de los oficiales públicos haría patente la escasa contundencia de las sentencias promulgadas, el estudio de las penas impuestas manifestaría un cierto rigor.

No obstante, bajo nuestro punto de vista los estudios ahora mencionados no pueden responder a dos cuestiones centrales: en primer lugar, ¿̇i los sistemas de control de los oficiales públicos en los territorios de la Monarquía Hispánica fueron tan «inútiles», por qué funcionaron durante tanto tiempo? Y, en segundo lugar, de ser cierta la poca utilidad de estas instituciones, ¿cómo podría explicarse la oposición que muchas de ellas tuvieron que padecer ${ }^{3}$ ?

El objetivo del presente artículo es tratar de dar respuesta a estas dos preguntas fundamentales. Para ello, emplearemos los fondos documentales - en su mayoría inéditos - relacionados con las sentencias dictadas por la Visita del General de Catalunya ${ }^{4}$ entre 1600 y 1714, preservados en el Archivo de la Corona de Aragón. Como

3. Sobre esta cuestión un excelente estudio en Heredia López (2017: 189-207).

4. La Visita del General de Catalunya fue la institución dedicada al control de los oficiales públicos de la Diputació del General de Catalunya o Generalitat, la diputación permanente de las Cortes Catalanas que desde 1359 y hasta 1714 estuvo al cargo de la recaudación de la mayoría de tributos del Principado de Cataluña. Así mismo, actuó como garante del pacto establecido entre el rey y los braços o estamentos, aplicando un férreo control constitucional a lo largo del período moderno, hasta su supresión coincidiendo con la rendición de Barcelona el 11 de

Ediciones Universidad de Salamanca / ㅛ Stud. his., H. ${ }^{a}$ mod., 41, n. 2 (2019), pp. 339-367 
tendremos ocasión de ver, gracias a la centralización y sistematización documental aplicada por los sucesivos archiveros de la Diputació del General de Catalunya durante la época moderna (López de Plaza, 2008: 48-56) será posible reconstruir en buena medida el recorrido de las sentencias de la Visita, desde su dictamen hasta su ejecución efectiva. El primer epígrafe lo dedicaremos al análisis cuantitativo de las sentencias: cuantas fueron publicadas, cuantas terminaron en absolución y cuantas en condena; qué oficiales fueron los más perseguidos por la acción de los visitadores y por qué; $y$, finalmente, constatar si existieron diferencias en cuanto a la procedencia de dichos oficiales en el momento de aplicar las sentencias. La segunda parte de nuestro trabajo analizará el proceso de ejecución de las sentencias, con el objetivo de responder a una pregunta sencilla de formular, pero difícil de responder: ¿ se ejecutó aquello juzgado? Todo ello nos llevará a la conclusión que difícilmente podemos describir la Visita del General de Catalunya como una institución «inútil» - hecho que ya fue evidenciado por los propios coetáneos ${ }^{5}$, antes bien: avanzamos que del estudio tanto de las sentencias promulgadas por la institución fiscalizadora, como de su proceso de ejecución se infiere más bien todo lo contrario.

septiembre de 1714 y la posterior entrada en vigor del Decreto de Nueva Planta el 16 de enero de 1716 - para un balance historiográfico sobre la Diputació del General vid. Ferrer i Mallol (2011) - . Por lo que respecta a la Visita del General de Catalunya, vid. fundamentalmente Llinás Almadana (1990: 177-192); Serra i Puig (2011: 165-184); Torra i Prat (2015: 295-317). La Visita del General - o Visita de la Generalitat, puesto que el vocablo «General» hace referencia a «Generalitat» y, por lo tanto, debería no confundirse con las «visitas generales» típicas de otros territorios de la Monarquía Hispánica - tenía lugar durante nueve meses una vez cada tres años, coincidiendo con la finalización del mandato del consistorio de los diputados y oidores de cuentas de la Generalitat. Los tres primeros meses de la inspección se dedicaban a la instrucción de los procesos, los tres siguientes a recibir las defensas de los acusados y los últimos tres a sentenciar las querellas.

5. Por ejemplo, durante las Cortes Catalanas de 1705-1706 los estamentos debatieron la posibilidad de crear un tribunal que uniera las competencias de la Visita del General, la Visita Real - esto es, la visita de los oficiales de la administración del rey en el Principado - y el Tribunal de Contrafaccions - el organismo que desde 1702 se encargaba de arbitrar las causas de contravención de la normativa pactada entre los estamentos y el monarca en Cortes - . Sin embargo, Josep Terré i Granollacs, miembro del estamento militar, interpuso un dissentiment - mecanismo que servía para paralizar la actividad parlamentaria mientras no se atendiera la cuestión que había motivado su puesta en marcha - aduciendo que, a lo largo de su historia, la Visita del General de Catalunya había «produits favorables effectes», recordando al resto de miembros de la asamblea que la institución había sido creada por sus ancestros con mucha «premeditación». La idea de crear el nuevo tribunal fue finalmente abandonada por los estamentos, que consideraron que la cuestión necesitaba debatirse en profundidad, cosa imposible debido a la estrechez de los plazos impuestos por el Archiduque Carlos de Austria. Cort General de Barcelona (1705-1706). Procés familiar del braç militar. (2016). Barcelona: Parlament de Catalunya - Generalitat de Catalunya, 513-519 y 626. Sobre el contexto político y económico general en el que se celebraron las Cortes Catalanas de 1705-1706 vid. Albareda (2010: 178-185). En cuanto al Tribunal de Contrafaccions, remitimos a Capdeferro i Pla y Serra i Puig (2015).

Ediciones Universidad de Salamanca / అ@@ Stud. his., H. ${ }^{a}$ mod., 41, n. 2 (2019), pp. 339-367 
RICARD TORRA-PRAT

EL QUID DE LA CUESTIÓN. SOBRE SENTENCIAS DE VISITA Y SU EJECUCIÓN:

EL CASO DE LA VISITA DEL GENERAL DE CATALUNYA, 1599-1711

\section{1. «PERÇÒ Y ALTRAMENT, ATTĖS LO SOBREDIT Y LO QUE·S DEU ATTÉNDRER, PRONUNCIAM, SENTENCIAM Y DECLARAM»: LAS SENTENCIAS DE LA VISITA DEL GENERAL DE CATALUNYA, $1600-1714$}

La culminación de todo el trabajo realizado por los consistorios de visitadores del General y de todos los oficiales que trienio tras trienio les asistían en la gestión de la institución fiscalizadora tenía como máximo exponente la publicación y ejecución de las sentencias. En efecto, como bien le recordaban los agentes fiscalizadores a Felipe IV en una letra fechada en Barcelona a 29 de noviembre de 1659, si las sentencias no se hacían efectivas

sería mejor serrar [sic] la Visita, pues vendrá ha gastar sin provecho, quedando los desórdenes sin remedio, los excessos sin reparo, los delitos sin castigo, la Generalidad sobre [e]star tan exausta a pique de acabarse, viudas, pupillos, comunidaes y conventos sin poder alcansar sus censales y, finalmente, lo padecerá en común todo el Principado; y lo ordenado y concedido en el dicho Capítulo primero [del Redreç de 1599] sería en vano ${ }^{6}$.

En este sentido, la importancia que para los visitadores tenía la publicación y la posterior ejecución de las sentencias les condujo en algún caso a querellarse contra los diputados y oidores de cuentas de la Generalitat - esto es, los máximos dirigentes de dicha institución-. A modo de ejemplo, durante la Visita celebrada en los años 1626 y 1627, los agentes fiscalizadores criticaron duramente la actitud de los consistoriales de la Generalitat que habían dirigido la institución durante el trienio de 1623-1624. Considerando probado que por su dejadez no se había procedido a cobrar las cantidades a las que habían sido condenados los oficiales de la Generalitat visitados durante 1623 y 1624, los visitadores les condenaron a enderezar la situación en el plazo de un año; de lo contrario, se les advertía que habrían de responsabilizarse de las cantidades impuestas a los condenados, un total de 1.591 libras, 6 sueldos y 10 dineros barceloneses ${ }^{7}$. Similarmente, inspección tras inspección, una vez publicadas las sentencias el procurador fiscal de la Visita presentaba la suplicación de ejecución de las mismas ante el consistorio de visitadores,

6. Archivo de la Corona de Aragón (en adelante ACA), Generalidad, Serie G, 6, 10, ff. $103 \mathrm{v}-106 \mathrm{r}$.

7. Sentencia de la querella nº9 de la Visita celebrada los años 1626-1627. ACA, Generalidad, Serie G, 8, 2, ff. 80v-81v. Para contextualizar el importe de estas condenas, cabe decir que un diputado de la Generalitat tenía estipulado un sueldo anual de 1.539 libras, 17 sueldos y 4 dineros. Cfr. Capitols resultants de las sentèntias fetas per los molt Illustres Senyors Visitadors del General de Cathalunya, acerca dels càrrechs dels officials de la casa de la Deputatió y General de Barcelona y altras publicadas en lo any MDCXXI. (1621). Barcelona: Jeroni Margarit, $\mathrm{f}$. 109 r.

Ediciones Universidad de Salamanca / అ@@ Stud. his., H. ${ }^{a}$ mod., 41, n. 2 (2019), pp. 339-367 
alegando que «importaria poch proferir sentèntias si aquellas no eran executadas». Normalmente, esta suplicación era rápidamente contestada mediante el decreto de ejecución pertinente, que bien podía referirse a un grupo de sentencias en general, bien a una sentencia en particular ${ }^{8}$.

En consecuencia, podemos estar de acuerdo en el hecho de que para los coetáneos la promulgación y posterior ejecución de las sentencias era un elemento de la máxima trascendencia. Conforme a ello, los datos extraídos del análisis de las sentencias promulgadas por la Visita del General de Catalunya entre 1600 y 1714 así lo prueban. Como bien se puede observar en el cuadro $n^{\circ} 1$, entre estas dos fechas se publicaron un total de 3.368 sentencias, 1.417 de las cuales terminaron en condena del oficial u oficiales juzgados, 1.680 en absolución y 271 fueron trasladadas al consistorio de diputados y oidores de cuentas de la Generalitat, al considerarse que no habían sido lo suficientemente desarrolladas como para emitirse la sentencia en firme. La evolución en número total de sentencias publicadas por la Visita del General cada trienio a su vez nos permite explicar en buena medida la historia de la institución. En este sentido, el cuadro $\mathrm{n}^{\circ} 1$ recoge cinco grandes períodos: 1600-1640, 1640-1652, $1652-1660,1660-1701$ y $1701-1714$.

Cuadro nº 1 . Sentencias de la Visita del General, 1600-1714

\begin{tabular}{|c|c|c|c|c|}
\hline Período & Absolutorias & Condenatorias & $\begin{array}{c}\text { Traslado } \\
\text { Generalitat }\end{array}$ & Total \\
\hline $1600-1640$ & $833(55,94 \%)$ & $594(39,89 \%)$ & $62(4,16 \%)$ & $1.489(100 \%)$ \\
\hline $1640-1652$ & $199(55,12 \%)$ & $105(29,08 \%)$ & $57(15,78 \%)$ & $361(100 \%)$ \\
\hline $1652-1659$ & $185(35,10 \%)$ & $264(50,09 \%)$ & $78(14,80 \%)$ & $527(100 \%)$ \\
\hline $1659-1702$ & $406(53,07 \%)$ & $323(42,22 \%)$ & $36(4,70 \%)$ & $765(100 \%)$ \\
\hline $1702-1714$ & $57(25,22 \%)$ & $131(57,96 \%)$ & $38(16,81 \%)$ & $226(100 \%)$ \\
\hline $1600-1714$ & $1.680(49,88 \%)$ & $1.417(42,07 \%)$ & $271(8,04 \%)$ & $3.368(100 \%)$ \\
\hline
\end{tabular}

Fuente: Elaboración propia a partir de los registros de sentencias de la Visita del General'.

8. Este último extremo es el caso, por ejemplo, del decreto de ejecución de la sentencia contra Jaume Puig y Francesc Ramoneda, taulers (tablajeros) de Terrassa, elaborado durante la Visita de 1602-1603. ACA, Generalidad, Serie VG, 26, f. 4223.

9. ACA, Generalidad, Serie VG, 21 (1600-01); 26 (1602-03); 33 (1605-06); 37, 38, 212 (1608-09); 214 (1611-12); 58 (1614-15); 70 (1620-21); 79 (1623-24). ACA, Generalidad, Serie G, 8, 2 (1626-27); 1 (1629-30\&1632-33); 5 (1638-39\&1641-42); 4 (1644-45\&1647-48\&1650-51); 3 (1654-55); 6 (1656-57); 7 (1659-60\&1662-63); 8 (1665-66); 9 (1668-69\&1671-72); 10 (167475\&1677-78\&1680-81); 11 (1683-84); 12 (1686-87); 13 (1689-90\&1692-93); 14 (1695-96\&169899); 15 (1701-02); 16 (1704-05); 17 (1707-08); 18 (1710-11).

Ediciones Universidad de Salamanca / అ@@ Stud. his., H. ${ }^{a}$ mod., 41, n. 2 (2019), pp. 339-367 
RICARD TORRA-PRAT

EL QUID DE LA CUESTIÓN. SOBRE SENTENCIAS DE VISITA Y SU EJECUCIÓN:

EL CASO DE LA VISITA DEL GENERAL DE CATALUNYA, 1599-1711

En primer lugar, entre 1600 y 1640 podemos observar un período caracterizado por la elevada producción de sentencias - de media 124 por fiscalización-, que coincide con los años de crecimiento de la institución (Torra Prat, 2016: 249-279). La explicación de las cifras aquí mostradas reside en el potencial que la institución demostró tener durante las primeras décadas del siglo XVII, siendo capaz no sólo de hacer prevalecer sus intereses frente a los envites jurisdiccionales planteados por las demás instituciones del Principado, sino también publicando diversos impresos como consecuencia de su actividad fiscalizadora. ${ }^{10}$

Segundamente, las fiscalizaciones comprendidas entre 1640 y 1652 se caracterizaron por un descenso más que notable en cuanto al número de sentencias publicadas. En efecto, si durante los primeros cuarenta años de la centuria la media de resoluciones decretadas por cada fiscalización se situó al entorno de 124, entre 1640 y 1652 la cifra se redujo hasta poco más de 90 sentencias por Visita. Este descenso tiene una explicación harto sencilla: el período ahora mencionado coincide con el estallido y desarrollo de la Guerra dels Segadors (1640-1652), conflicto que acarreó por vez primera la introducción de limitaciones económicas y procedimentales en la Visita del General. ${ }^{11}$

Un tercer período se inicia inmediatamente después del retorno del Principado a la obediencia de Felipe IV en 1652 y finaliza en 1660 con la entrada en vigor de la Real Orden de 14 de abril de $1660^{12}$, referente a la aceptación de recursos contra las sentencias de la Visita del General consideradas «notoriamente injustas» ante la Real Audiencia de Cataluña. (Torra i Prat, 2014: 124) ${ }^{13}$. Durante estos años se constata

10. Durante las primeras cinco décadas del siglo XVII, los visitadores publicaron tres impresos dedicados a los oficiales de la Generalitat, Galeras de la Generalitat y Tablajeros de la Generalitat, respectivamente. Son los que siguen: Capitols y desliberations resultants de las sentèntias fetas per los Molt Illustres Senyors Visitadors del General de Cathalunya acerca dels càrrechs dels officials de la Squadra de las Galeras de Cathalunya y altras subjectes a la present visita: publicadas en lo any MDCXXI. (1621). Barcelona: Jeroni Margarit; Capitols resultants de las sentèntias fetas per los molt illustres senyors visitadors del General de Cathalunya acerca dels càrrechs dels officials de la Casa de la Deputació y General de Barcelona y altres publicades en lo any MDCXXI. (1657) Barcelona: Jeroni Margarit; Summari dels càrrechs y obligations, dels collidors, taulers, o receptors, dels drets de la Generalitat, del present Principat de Cathalunya, y comptats de Rosselló y Cerdanya, per Capitol de Corts, Ordinations del Generals, y per sentèntias de visitas, inposadas. (1657). Barcelona: Catharina Mathevad.

11. ACA, Generalidad, Serie G, 6, 6, ff. 6r-7v.

12. ACA, Generalidad, Serie G, 6, 10, ff. 148r-148v.

13. Antes de la reforma, las sentencias de la Visita se consideraban inapelables en virtud del Capítulo 1 del Redreç de 1599. Capitols per lo redrés del General y Casa de la Deputació de Cathalunya, fets en las Corts celebrades en lo Monestir de Sant Francesch de Barcelona per la S.C.R.M. del Sereníssim Senyor Rey Don Felip II de Aragó y III de Castella, en lo any 1599. (1704). Barcelona: Rafel Figueró, 4-10. Los Capítulos del Redreç, eran aquellas disposiciones aprobadas en el marco de las Cortes Catalanas que, a propuesta de los estamentos y con el

Ediciones Universidad de Salamanca / @®@@ Stud. his., H. ${ }^{a}$ mod., 41, n. 2 (2019), pp. 339-367 
un aumento notable de las sentencias promulgadas por los sucesivos consistorios de visitadores, con una media de más de 175 sentencias por cada inspección. La explicación de este aumento reside, como veremos más adelante, en el notable incremento de las sentencias relacionadas con los tablajeros de la Generalitat - oficiales recaudadores repartidos a lo largo de todo el territorio catalán-. En este sentido, en las Visitas de 1654-1655, 1656-1657 y 1659-1660 se publicaron una media de 104 sentencias contra los tablajeros, mientras que, durante los primeros cuarenta años del siglo XVII, las cifras se sitúan al entorno de 40 sentencias por fiscalización.

El cuarto período por lo que a la producción de las sentencias se refiere, se inicia en 1662 y termina en 1702, coincidiendo con el cambio de dinastía y la celebración de las Cortes Catalanas de 1701-1702. Durante este ciclo puede observarse en primer lugar una progresiva reducción en el número de sentencias publicadas, seguida de una fase de estancamiento. Bajo nuestro punto de vista todo ello es consecuencia del progresivo deterioro de la institución fruto de las reformas introducidas por la monarquía en materia tanto en los procesos de elección de los oficiales de la institución ${ }^{14}$, como en la limitación de sus gastos ${ }^{15}$ (Torra i Prat, 2014: 125-128). En este sentido, si durante el ciclo comprendido entre 1600 y 1640 la media de sentencias promulgadas fue, como hemos dicho, de 124, entre 1662 y 1702 no llegó a 55 sentencias por cada fiscalización.

Finalmente, el quinto y último período cubre aquellas visitas celebradas con posterioridad a las Cortes Catalanas de 1701-1702 y hasta la supresión de la institución en 1714. Cabe destacar aquí que, a pesar la existencia de un repunte en la producción de sentencias, especialmente durante las visitas de 1704-1705 y 17071708, las fiscalizaciones del período tuvieron lugar en un contexto bélico que, a la fuerza, tuvo que influir en su resultado final. No obstante, durante estos años se publicaron una media de más de 93 sentencias por visita, cifras que, si bien distan de las de los primeros cuarenta años del siglo XVII, representan un incremento considerable respecto a las del período inmediatamente precedente. Todo ello fue debido, muy probablemente, a las reformas que las Cortes Catalanas de 1701-1702 y 1705-1706 introdujeron a la Visita del General, reformas que en buena medida revirtieron el camino trazado por el intervencionismo real durante la segunda mitad del siglo anterior (Torra i Prat, 2014: 128-131).

placet del monarca, hacían referencia exclusiva al ámbito jurisdiccional de la Generalitat. Cfr. Oleart, 1993: 245.

14. Real Orden de 18 de julio de 1665 por la que se reforma la provisión de los oficios de la Visita del General de Catalunya. ACA, Generalidad, Serie G, 6, 12, ff. 4/2 ${ }^{\mathrm{a}}-4 / 4^{\mathrm{a}}$.

15. Real Orden de 14 de julio de 1668 por la que se reforman los gastos de la Visita del General de Catalunya. Dietaris de la Generalitat de Catalunya, vol. VII. (2002). 1305-1306.

Ediciones Universidad de Salamanca / అ@@ Stud. his., H. ${ }^{a}$ mod., 41, n. 2 (2019), pp. 339-367 


\subsection{El veredicto según el origen territorial de los oficiales}

Uno de los elementos más interesantes a la hora de analizar los datos obtenidos a partir del vaciado de los registros de sentencias de la Visita del General es el de poder determinar hasta qué punto el origen territorial de los oficiales fiscalizados tuvo o no influencia en el veredicto. Para ello, hemos distinguido entre aquellos oficiales de la demarcación fiscal de Barcelona y los llamados «forans», esto es, los que ejercían su oficio fuera de dicha demarcación. ${ }^{16}$. En este sentido, entre 1600 y 1714 de un total de 3.368 sentencias publicadas, un $53 \%$ (1.770) afectaron a oficiales «forans», mientras que el 47\% (1.598) restante fueron dirigidas a los oficiales de la demarcación fiscal de Barcelona. Estos datos contrastan significativamente con los del período comprendido entre 1600 y 1652, cuando de un total de 1.850 sentencias, el 49,91\% (924) afectaron a oficiales barceloneses y el 50,02\% (926) restante implicó a oficiales «forans». Esta diferencia entre el período 1600-1652 y el resto de la serie histórica se debe principalmente al progresivo aumento del peso de las sentencias promulgadas contra los tablajeros del General respecto al resto de oficiales de la Diputació durante la segunda mitad del siglo XVII y principios del XVIII. En efecto, si entre 1600 y 1652 las sentencias contra estos oficiales recaudadores representaron un $36,16 \%$ del total (669 de 1.850), entre 1652 y 1714 aumentaron hasta un 51,91\% (788 de 1.518). Como consecuencia, entre 1652 y 1714 la correlación de sentencias publicadas contra oficiales «forans» y oficiales barceloneses se situó en torno al $55,59 \%$ (844 de 1.518 ) - 44,40\% (674 de 1.518), respectivamente.

Un segundo elemento interesante es el de la correlación entre aquellas sentencias que terminaron en condena, aquellas que lo hicieron en absolución y aquellas que fueron trasladadas al consistorio de diputados y oidores de cuentas para mayor averiguación de los cargos presentados durante el proceso. De los datos recogidos en el cuadro $\mathrm{n}^{\circ} 1$ se infiere que entre 1600 y 1714 una mayoría de las sentencias concluyó con la absolución de los acusados, especialmente en el caso de aquellas visitas comprendidas entre 1600 y 1652 y 1659 y 1702. Por el contrario, resulta evidente que durante los períodos comprendidos entre 1652 y 1659 y 1702 y 1714 la mayor parte de las sentencias fueron condenatorias. En este sentido, a diferencia del aumento del total de las sentencias - por ejemplo, atribuible, como hemos visto, al aumento de sentencias dirigidas contra un determinado colectivo-, el aumento del porcentaje en el caso de las condenas parece no tener una explicación simple: bajo nuestro punto de vista, dicho crecimiento se debió más a razones coyunturales $-¿$ Quizás visitadores más estrictos? ¿U oficiales más negligentes? -, que estructurales.

16. El listado de los oficiales y sus obligaciones en Capitols resultants de las sentèncias, ff. $1 \mathrm{r}-107 \mathrm{v}$.

Ediciones Universidad de Salamanca / 요 Stud. his., H. ${ }^{a}$ mod., 41, n. 2 (2019), pp. 339-367 
Sin embargo, estas cifras se muestran un tanto distintas si atendemos a la procedencia territorial de los oficiales sentenciados. En el cuadro $\mathrm{n}^{\circ} 2$ se especifican las sentencias que afectaron los oficiales barceloneses:

Cuadro n 2. Sentencias de la Visita del General, oficiales de Barcelona, 1600-1714

\begin{tabular}{|c|c|c|c|c|}
\hline Período & Absolutorias & Condenatorias & Traslado & Total \\
\hline $1600-1640$ & $529(68,43 \%)$ & $213(27,55 \%)$ & $31(4,01 \%)$ & $773(100 \%)$ \\
\hline $1640-1652$ & $101(66,88 \%)$ & $24(15,89 \%)$ & $26(17,21 \%)$ & $151(100 \%)$ \\
\hline $1652-1659$ & $108(53,20 \%)$ & $83(40,88 \%)$ & $12(5,91 \%)$ & $203(100 \%)$ \\
\hline $1659-1702$ & $257(60,32 \%)$ & $156(36,61 \%)$ & $13(3,05 \%)$ & $426(100 \%)$ \\
\hline $1702-1714$ & $26(57,77 \%)$ & $15(33,33 \%)$ & $4(8,88 \%)$ & $45(100 \%)$ \\
\hline $1600-1714$ & $1.021(63,89 \%)$ & $491(30,72 \%)$ & $86(5,38 \%)$ & $1.598(100 \%)$ \\
\hline
\end{tabular}

Fuente: Elaboración propia a partir de los registros de sentencias de la Visita del General.

Como podemos constatar, entre 1600 y 1714 el 63,89\% (1.021) del total de las sentencias (1.598) concluyeron con la absolución de los acusados y el 30,72\% (491) en condena, mientras que el 5,38\% (86) restante fueron trasladadas al consistorio de los diputados y oidores de cuentas para mayor averiguación de los cargos presentados durante el proceso.

Contrariamente, en el caso de las querellas que afectaron a los oficiales «forans» - cuadro $\mathrm{n}^{\circ} 3$-, observamos como las absoluciones se reducen hasta el $37,23 \%$ (659), mientras que las condenas suben hasta un notable 52,31\% (926), y aquellas que terminaron en traslado se sitúan en el 10,45\% (185) del total (1.770).

Cuadro no 3. Sentencias de la Visita del General, oficiales forans, 1600-1714

\begin{tabular}{|c|c|c|c|c|}
\hline Período & Absolutorias & Condenatorias & Traslado & Total \\
\hline $1600-1640$ & $304(42,45 \%)$ & $381(53,21 \%)$ & $31(4,32 \%)$ & $716(100 \%)$ \\
\hline $1640-1652$ & $98(46,66 \%)$ & $81(38,57 \%)$ & $31(14,76 \%)$ & $210(100 \%)$ \\
\hline $1652-1659$ & $77(34,37 \%)$ & $181(55,86 \%)$ & $66(20,37 \%)$ & $324(100 \%)$ \\
\hline $1659-1702$ & $149(43,95 \%)$ & $167(49,26 \%)$ & $23(6,78 \%)$ & $339(100 \%)$ \\
\hline $1702-1714$ & $31(17,12 \%)$ & $116(64,08 \%)$ & $34(18,78 \%)$ & $181(100 \%)$ \\
\hline $1600-1714$ & $659(37,23 \%)$ & $926(52,31 \%)$ & $185(10,45 \%)$ & $1.770(100 \%)$ \\
\hline
\end{tabular}

Fuente: Elaboración propia a partir de los registros de sentencias de la Visita del General.

Los datos ahora mencionados evidencian una cuestión fundamental: mientras que la correlación entre sentencias publicadas contra los oficiales «forans» y oficiales

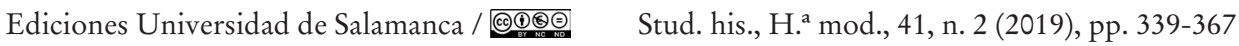


barceloneses para la serie histórica no presenta unas diferencias sustanciales y puede explicarse por la mayor cantidad de oficiales «forans» - especialmente tablajeros-, la disimilitud en los porcentajes de condenas dependiendo del origen territorial de los oficiales sí permite concluir que, durante los años en los que la Visita del General de Catalunya estuvo vigente, existió una tendencia a actuar más severamente contra los oficiales «forans» que contra los barceloneses.

Bajo nuestro punto de vista, cuatro grandes hipótesis permiten explicar la existencia de esta diferencia: 1 . En primer lugar, el hecho de que gran parte de los oficiales «forans» tuvieron dificultades para acceder a la legislación relacionada con su oficio, especialmente en el caso de los oficiales de menor rango tablajeros y guardas del General. Por lo que a los tablajeros respecta, esta situación se intentó revertir con la publicación de un impreso dedicado exclusivamente a su figura. ${ }^{17}$. 2. Segundamente, cabría destacar que, en la mayoría de los casos, las disfunciones administrativas cometidas por los oficiales «forans» estaban mucho mejor delimitadas en los compendios legales de la Generalitat y, como consecuencia, eran más fácilmente fiscalizables (y condenables). Buena prueba de ello son las sentencias cada vez más detalladas contra los tablajeros durante los últimos años del siglo XVII y principios del XVIII ${ }^{18}$. 3. En tercer lugar, entendemos que, por lo general, los oficiales «forans» se caracterizaron por proceder de estratos sociales inferiores a los de los oficiales de Barcelona, hecho que los llevó a usar operadores jurídicos de menor calidad $-o$, directamente a renunciar a su defensa- mermando de esta manera sus opciones de sobreponerse a las acusaciones presentadas por los visitadores ${ }^{19} .4$. Finalmente, en cuarto y último lugar, creemos que es oportuno preguntarse hasta qué punto alteró el resultado de las sentencias el hecho que los oficios barceloneses de la Generalitat estuvieran tradicionalmente ocupados por miembros de la clase dirigente barcelonesa, cuyo poder de influencia fue, sin duda, importante (Martí Fraga, 2009: 126 ${ }^{20}$.

17. Summari dels càrrechs (1657).

18. Sirva de ejemplo la sentencia de la Visita de 1707-1708 contra Joan Virgili, tablajero de Torredembarra, al que se le imputaron un total de catorce delitos, doce de los cuáles de carácter administrativo, como por ejemplo no haber numerado las hojas de sus libros de cuentas. ACA, Generalidad, Serie G, 8, 17, ff. 26r-29v.

19. Por ejemplo, según los Capitols resultants de las sentèncias, (f. 109r) los oficiales barceloneses mejor retribuidos eran los diputados y los oidores de cuentas. Contrariamente, el salario de los tablajeros del General encargados de las tablajerías «foranes» se deducía en base a los derechos recaudados en su puesto fiscal, establecido en un diez por ciento del total. Ello conllevaba que las tablajerías en dónde existía una actividad comercial más dinámica fuesen las más deseadas, puesto que las opciones de enriquecerse eran mucho mayores. Capitols per lo Redrés, 128-129. 1986.

20. Sobre la clase dirigente catalana hoy en día es aún indispensable el estudio de: Amelang,

Ediciones Universidad de Salamanca / 요 Stud. his., H. ${ }^{a}$ mod., 41, n. 2 (2019), pp. 339-367 


\subsection{Las sentencias y los oficiales. La preponderancia de los diputados y oidores de} cuentas y los tablajeros

El estudio de las sentencias promulgadas por la Visita del General de Catalunya también permite constatar la existencia de notables diferencias a nivel cuantitativo dependiendo de los oficiales de la Generalitat en los que fijemos nuestra atención: en este sentido, resulta evidente que diputados y oidores de cuentas por un lado, y tablajeros del General por el otro fueron los servidores públicos que capitalizaron la mayoría de las sentencias decretadas por la institución fiscalizadora. En efecto, ambos grupos de oficiales protagonizaron 2.436 sentencias entre 1600 y 1714, esto es, el $72,32 \%$ del total (3.368). Si nos fijamos en su evolución a lo largo de todas las visitas de las que disponemos de datos fehacientes, cabe decir que existen diferencias entre ambos colectivos de oficiales. Así, el número de sentencias promulgadas contra los dirigentes de la Diputación - gráfico 1- parece demostrar dos tendencias evidentes, con un mayor número de publicaciones por cada Visita entre 1600 y 1680 - a excepción del período de la Guerra dels Segadors y algunas fiscalizaciones como las de 1623, 1632 y 1654 donde las sentencias se disparan-. La explicación del progresivo declive de las sentencias coincidiendo con los últimos años de vida de la institución, muy probablemente se debió a las reformas que la Monarquía Hispánica introdujo en la Visita a partir de 1660.

Gráfico n 1 . Sentencias contra diputados y oidores de cuentas, 1600-1714

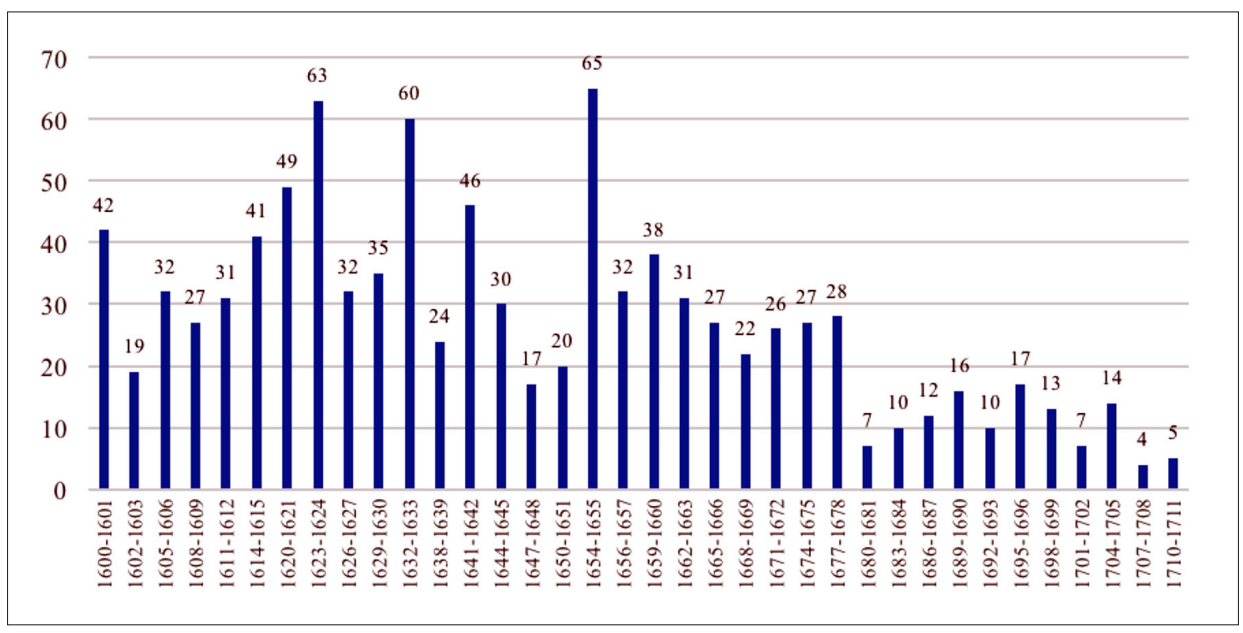

Fuente: Elaboración propia a partir del registro de sentencias de la Visita del General. 
En cuanto a las sentencias promulgadas contra los tablajeros del General - gráfico n² - su evolución durante el período analizado es, como hemos afirmado anteriormente, distinta: por un lado, entre 1605 y 1652 se mantiene más o menos estable al entorno de las 50 sentencias por fiscalización, seguida de un pico durante las dos visitas que preceden a la publicación del impreso dedicado a los tablajeros del General; por otro lado, cabe decir que parecen desaparecer por completo durante la década de 1668-1678 para recuperarse tímidamente entre 1680 y 1700 y volver a crecer coincidiendo con el cambio de siglo.

Gráfico n 2. Sentencias contra tablajeros del General, 1600-1714

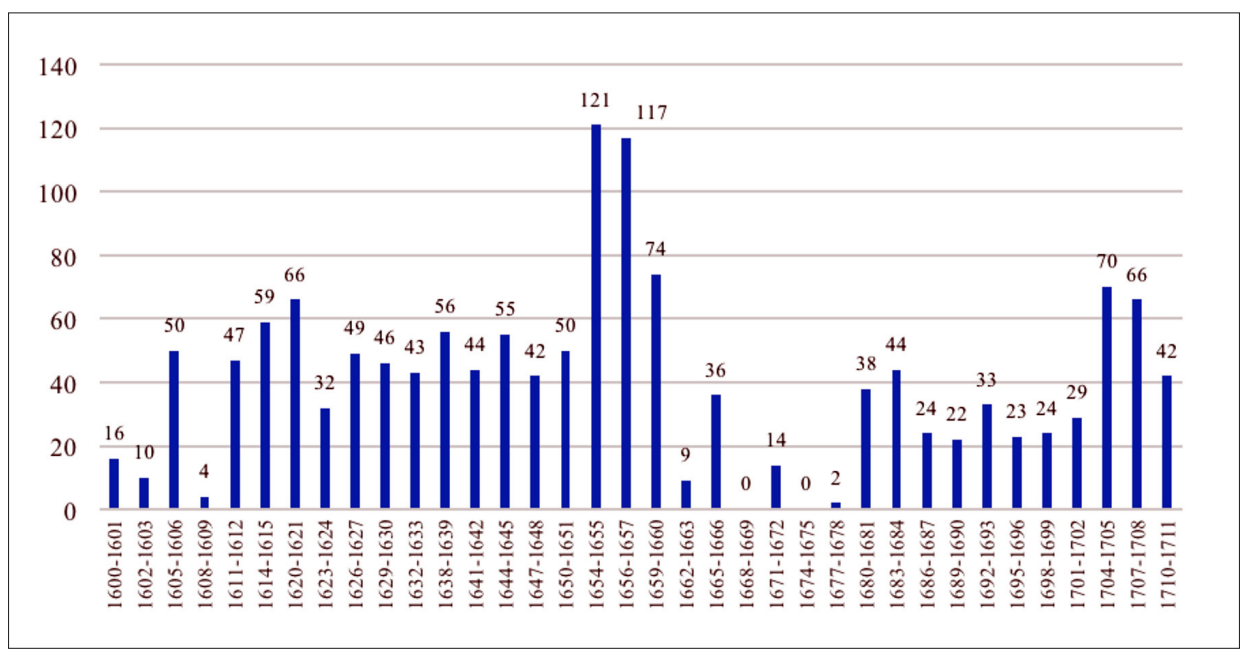

Fuente: Elaboración propia a partir del registro de sentencias de la Visita del General.

Determinar las razones por las que se produjo el drástico descenso de las sentencias contra los tablajeros durante el decenio de 1668-1678 es una tarea muy complicada, puesto que ni el registro de sentencias de la Visita ni los dietarios de la institución hacen ninguna mención a esta situación. No obstante, pensamos que la explicación muy probablemente resida en el escaso presupuesto de la Visita, hecho que fue denunciado en varias ocasiones por los agentes fiscalizadores durante estos años ${ }^{21}$. Por lo que respecta al período comprendido entre 1680 y 1700 , es evidente que, si bien existió una tímida recuperación del número de sentencias, en ningún

21. Baste, como muestra, la letra enviada por los visitadores al virrey, duque de Osuna, el 9 de abril de 1669. ACA, Generalidad, Serie G, 6, 13, ff. 145r-146v.

Ediciones Universidad de Salamanca / @®@@ Stud. his., H. ${ }^{a}$ mod., 41, n. 2 (2019), pp. 339-367 
caso estamos hablando de cifras parecidas a las de la primera mitad del siglo XVII. En este sentido, a la antes mencionada tendencia decreciente por lo que a sentencias de la Visita se refiere, cabría sumar otras dos razones para explicar los bajos índices de resoluciones contra tablajeros: en primer lugar, el hecho que entre 1680 y 1690 las querellas y sentencias contra estos oficiales tendieron a agruparse - contrariamente a lo sucedido durante las primeras décadas de la centuria, dónde los visitadores tendieron a publicar una sentencia por cada tablajería inspeccionada ${ }^{22}-$. En segundo lugar, el hecho que los tablajeros alegaran como consuetudinarias muchas de las prácticas irregulares denunciadas por los visitadores a partir de 1660. Esta situación llegó a estar tan generalizada que las Cortes de 1701-1702 decidieron remediarla mediante la promulgación de la Constitución 26/1702, declarando «nullos e irritos» cualesquiera «usos y costums contra los Usatges, Constitucions, Capitols y Actes de Cort» ${ }^{23}$.

Las diferencias entre diputados y oidores de cuentas por un lado, y tablajeros por el otro lado, parecen ser aún más significativas si focalizamos nuestra atención en la correlación entre aquellas sentencias que terminaron en condena, aquellas que lo hicieron en absolución y aquellas que fueron trasladadas a la Generalitat. Así, podemos observar que en el caso de los diputados y los oidores de cuentas - gráfico n ${ }^{\circ} 3$ - en un $66 \%$ (643) de las ocasiones las sentencias concluyeron con la absolución de los acusados, en un $28 \%$ (274) en condena y en un 6\% (62) se optó por posponer la decisión trasladando la querella.

Por el contrario, en el caso de los tablajeros - gráfico $n^{\circ} 4-$ la mayoría de las querellas, un $53 \%$ (782), concretamente, terminaron en condena, un $36 \%$ (520) en absolución y un $11 \%$ (156) fueron trasladadas a la Generalitat. Bajo nuestro punto de vista, la explicación de las diferencias observadas entre los oficiales ahora analizados reside en buena medida en las mismas razones que explicarían la disimilitud existente al comparar el veredicto de las sentencias dirigidas contra oficiales barceloneses y oficiales «forans», esto es, una suma de factores entre los cuales la estrechez económica de los tablajeros juntada con el desconocimiento de la normativa aplicable a su oficio, nos parecen los más destacables.

22. Sirva de ejemplo la sentencia de la querella n54 de la Visita de 1686-1687, que implicó a Joan March y Joan Anseguet, tablajeros de Manresa, Joan Martí, tablajero de Calaf, Josep Vallosera, tablajero de Castellterçol, Jaume Sastre, tablajero de Sant Llorenç de Morunys, Diego Sobrequés, tablajero de Torà, Francesc Planes, tablajero de Sant Feliu Sasserra, Jaume Datzira, tablajero de Moià y Jaume Vilasseca, tablajero de Sallent. ACA, Generalidad, Serie G, 8, 12, ff. $32 \mathrm{v}-33 \mathrm{r}$ y $41 \mathrm{v}-44 \mathrm{v}$.

23. Constitutions, capitols y actes de Cort, fetas y atorgats per la S.C.R. Magestat del rey nostre senyor don Felip IV de Aragó y $V$ de Castella, comte de Barcelona et etc. En la primera Cort celebrada als cathalans en la ciutat de Barcelona en lo Monastir de Sant Francesch, en los anys 1701 y 1702. (1702). Barcelona: Rafel Figueró, 16-17.

Ediciones Universidad de Salamanca / @®@@ Stud. his., H. ${ }^{a}$ mod., 41, n. 2 (2019), pp. 339-367 
Gráfico no 3 . Sentencias contra diputados y oidores de cuentas, 1600-1714

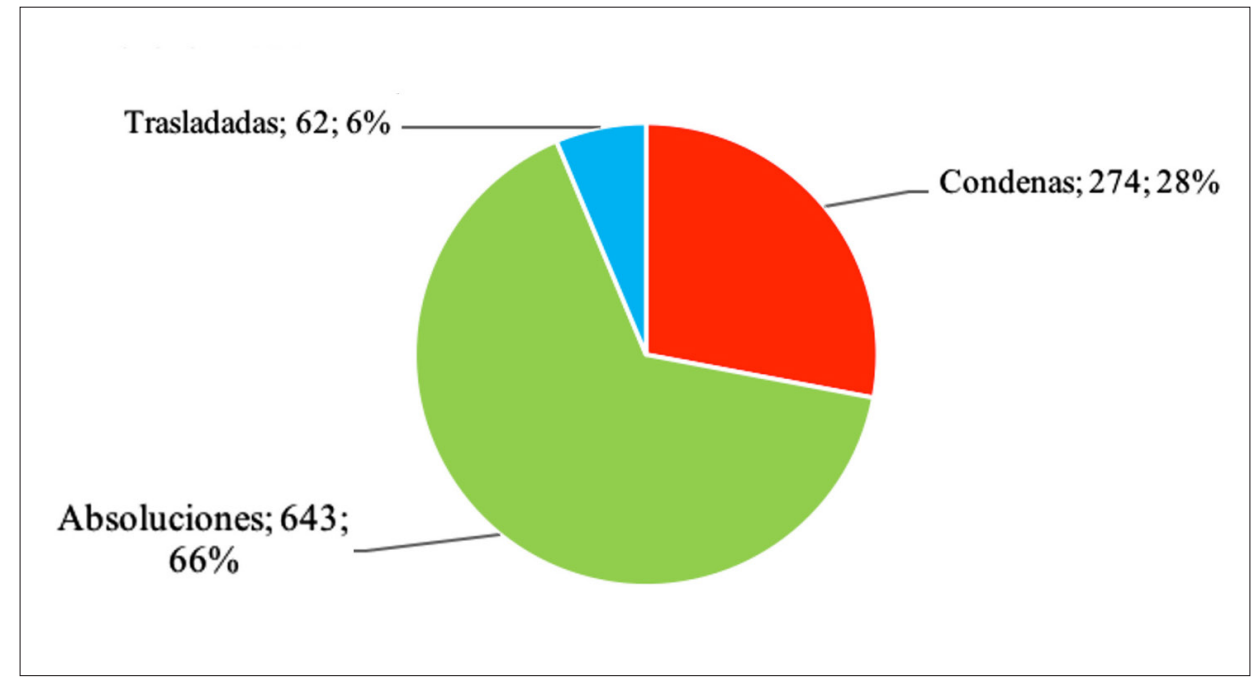

Fuente: Elaboración propia a partir del registro de sentencias de la Visita del General.

Gráfico nº 4. Sentencias contra tablajeros del General, 1600-1714

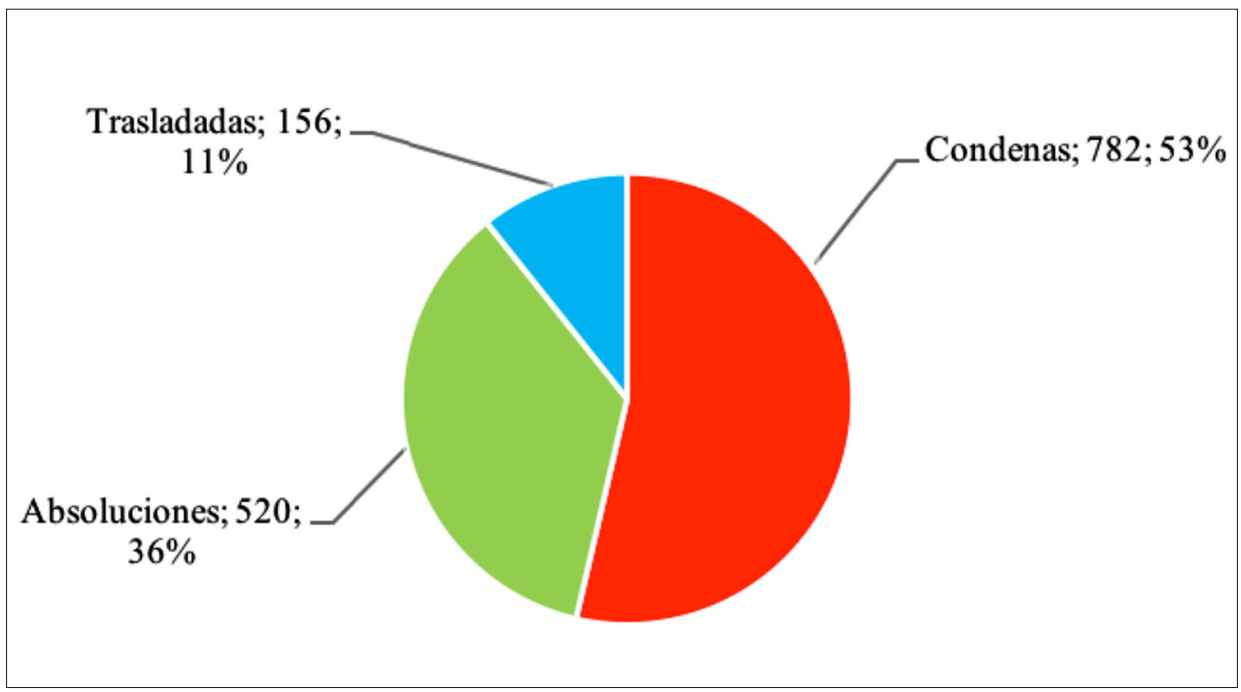

Funte: Elaboración propia a partir de los registros de sentencias de la Visita del General.

Ediciones Universidad de Salamanca / @ఠ Stud. his., H. ${ }^{a}$ mod., 41, n. 2 (2019), pp. 339-367 
RICARD TORRA-PRAT

EL QUID DE LA CUESTIÓN. SOBRE SENTENCIAS DE VISITA Y SU EJECUCIÓN:

EL CASO DE LA VISITA DEL GENERAL DE CATALUNYA, 1599-1711

\section{2. «IMPORTARIA POCH PROFERIR SENTÈNTIAS SI AQUELLAS NO ERAN EXECUTADAS». ¿HASTA QUÉ PUNTO FUERON APLICADAS LAS SENTENCIAS DE LA VISITA?}

La inspección dirigida por los visitadores se celebraba una vez cada tres años, coincidiendo con el inicio de un nuevo trienio en el consistorio de diputados y oidores de cuentas de la Generalitat, momento en el cual los nuevos dirigentes de la institución accedían a sus oficios. En este sentido, la Visita se dirigía contra los oficiales de la Generalitat que habían ejercido sus funciones en el trienio precedente. Para ello, durante nueve meses improrrogables, los agentes fiscalizadores recibían las denuncias, las fortificaban, formulaban las acusaciones, recibían y estudiaban las defensas de los acusados, juzgaban las querellas y, finalmente, emitían las sentencias pertinentes. Aunque la jurisdicción de los visitadores prescribía coincidiendo con la publicación de los decretos de ejecución de las sentencias, se les permitía seguir con las reuniones del consistorio con el objetivo de asegurar, precisamente, dicha ejecución, puesto que se consideraba un paso clave en todo el proceso. Más aún, era concebida como la culminación sin la cual todo el trabajo desarrollado por la institución carecía de significado. En este sentido, la ejecución de las sentencias significaba tanto la aplicación de los castigos que los visitadores habían decidido imponer contra aquellos oficiales de la Generalitat que habían lesionado la ley vigente, como la reparación y/o mejora de esta - para ello tendieron a usar la parte final de las sentencias para registrar exhortaciones dirigidas a corregir la mala praxis de los oficiales públicos y que debían ser atendidas como si de leyes aprobadas en Cortes se tratara-. Sin embargo, ¿cómo funcionaba el proceso de ejecución de las sentencias? ¿A qué oficiales implicaba? Y más importante aún, ¿hasta qué punto se ejecutaron las sentencias? A lo largo de las páginas siguientes nos proponemos responder a estos interrogantes.

\section{1. "Una nova e imaginada defensa»: la efectividad de la suplicación y la apelación antes del decreto de ejecución de las sentencias}

Terminada la ceremonia de publicación de las sentencias de la Visita, el procurador fiscal de la institución fiscalizadora suplicaba con celeridad su ejecución ${ }^{24}$. Como bien recoge el Directori de la Visita del General de 1636, los visitadores consideraban de vital importancia proceder a la ejecución de las sentencias con rapidez, tratando de evitar con ello «la gran negociació que fan los querelats condemnats per a que se.ls reparen los prejudicis que diuen han rebut en las sentèncias» ${ }^{25}$. Esta

24. ACA, Generalidad, Serie VG, 26, f. 4217r.

25. Directori de la Visita del General de Catalunya y breu sumari de sentèncias de las Visitas fetas desde lo any 1599 fins la última feta en lo any 1635, que importan dispositió en lo esdevenidor en benefici del General. (1636). Barcelona: Gabriel Nogués, 18.

Ediciones Universidad de Salamanca / అ@@ Stud. his., H. ${ }^{a}$ mod., 41, n. 2 (2019), pp. 339-367 
negociación aludida por los dirigentes de la Visita se refería a la práctica por parte de los condenados de presentar suplicaciones contra las sentencias antes que fuera promulgado el decreto de ejecución, buscando con ello la reducción o, directamente la eliminación, de la condena. En este sentido, entre 1600 y 1700 hemos podido identificar un total de 373 suplicaciones, de las cuales el 45,30\% (169) fueron aceptadas y el $29,22 \%$ (109) rechazadas, mientras que por lo que respecta al $25,46 \%$ (95) restante, la documentación no permite dilucidar cual fue el resultado. En cuanto a la efectividad de la suplicación como medio para alterar las sentencias de la Visita, esta se situó al entorno del 13,37\%, considerando que solamente se aceptó en 169 condenas de un total de 1.264 para el período 1600-1714.

Cuadro ${ }^{\circ}$ 4. Suplicaciones contra sentencias de la Visita del General, 1600-1714

\begin{tabular}{|c|c|c|c|c|}
\hline & Suplicaciones & Aceptadas & No Aceptadas & NS \\
\hline $1600-1640$ & 84 & 20 & 20 & 44 \\
\hline $1640-1652$ & 37 & 12 & 9 & 16 \\
\hline $1652-1659$ & 94 & 40 & 23 & 31 \\
\hline $1659-1702$ & 158 & 97 & 57 & 4 \\
\hline $1702-1714$ & 0 & 0 & 0 & 0 \\
\hline $1600-1714$ & 373 & 169 & 109 & 95 \\
\hline
\end{tabular}

Fuente: Elaboración propia a partir de ACA, Generalidad, Serie VG, 21, 26, 33, 37, 38, 212, 214, 58, 70, 79; y Serie G, 8, 1-18.

Por lo que respecta a los escritos de suplicación, cabe destacar su heterogeneidad. Así, mientras que unos se caracterizaron tanto por su brevedad, como por pedir solamente a los visitadores la moderación de la condena aplicada ${ }^{26}$, otros destacaron por su complejidad y, más que suplicaciones, verdaderamente parecían recursos contra la decisión de los agentes fiscalizadores ${ }^{27}$.

26. Este fue el caso, por ejemplo, del escrito presentado por Antoni Thió - escribano mayor de la Generalitat durante el trienio de 1623-1626 - contra la sentencia de la querella no61 de la Visita de 1626-1627. ACA, Generalidad, Serie G, 8, 2, ff. 25r-26v.

27. Sirva de ejemplo la suplicación que Baptista Morer, tablajero de Vilafranca de Conflent, presentó en 1639 ante el consistorio de la Visita contra la sentencia de las querellas nº48, 49, 50, 51 y 52. En su alegato, Morer expuso hasta cinco razones por las que consideraba que la decisión de los agentes fiscalizadores debía modificarse. Afortunadamente para sus intereses, los visitadores dieron validez - en parte - a sus explicaciones y la condena original - esto es, privación perpetua del oficio de tablajero - fue reducida en gran medida - finalmente se le condenó a suspensión del oficio durante doce meses y a entregar diversos documentos relacionados con la actividad al frente de la tablajería de Vilafranca de Conflent-. ACA, Generalidad, Serie G, 8, 5, ff. 90r-92r y 130 r. 
Es importante remarcar que hasta 1702 cabría situar la suplicación antes de la ejecución de las sentencias como una actividad alegal, puesto que sin ser un recurso al uso - procedimiento prohibido por la legislación tocante a la Visita-, sirvió como altavoz a aquellos condenados que consideraban que sus derechos habían sido lesionados por la resolución de los visitadores. Sin embargo, fue a partir de la promulgación del Capítulo 32 del Redreç de 1702 cuando las Cortes Catalanas establecieron un procedimiento de apelación incluido en el judiciario de la Visita que sustituyó tanto a las suplicaciones, como a los recursos que por causas de «notoria injusticia» se venían aceptando desde 1660 ante la Real Audiencia de Cataluña, esto es, la jurisdicción del rey ${ }^{28}$. Con ello, se resolvían las dos grandes dificultades que la Visita había padecido durante el siglo XVII en lo que a sentencias se refiere: por un lado, la gran cantidad de suplicaciones que los acusados presentaban fiscalización tras fiscalización días antes de la promulgación del decreto de ejecución; por otro lado, se eliminaba la posibilidad de presentar un recurso ante la Real Audiencia de Cataluña o, lo que es lo mismo, trasladar las causas de la jurisdicción del General a la jurisdicción real. Durante las cuatro visitas en las que el sistema de apelación estuvo vigente, se presentaron un total de 73 recursos, el 89,04\% (65) de los cuales confirmó la sentencia original, mientras que en el 10,95\% (8) restante se aceptaron las peticiones de los condenados.

Cuadro $n^{\circ}$ 5. Apelaciones contra sentencias de la Visita, 1700-1714

\begin{tabular}{|c|c|c|c|}
\hline & Recurso & Recurso confirmación & Recurso absolución \\
\hline $1701-1702$ & 7 & 5 & 2 \\
\hline $1704-1705$ & 23 & 20 & 3 \\
\hline $1707-1708$ & 26 & 24 & 2 \\
\hline $1710-1711$ & 17 & 16 & 1 \\
\hline $1701-1714$ & 73 & 65 & 8 \\
\hline
\end{tabular}

Fuente: Elaboración propia, ACA, Generalidad, Serie G, 8, 15-18.

Para finalizar, bajo nuestro punto de vista, podemos hacer tres grandes reflexiones entorno los sistemas de suplicación y apelación arriba analizados. En primer lugar, cabría destacar el peso relativo que tuvieron en el global de sentencias condenatorias publicadas por la Visita del General entre 1600 y 1714. En efecto, como hemos podido constatar, entre 1600 y 1700 las suplicaciones finalmente aceptadas solamente afectaron a un $13,37 \%$ del total de las condenas publicadas por la Visita; de manera análoga, entre 1702 y 1714 las apelaciones atañeron al 10,95\% del total de

28. Constitucions, Capitols y Actes de Cort, 57-64.

Ediciones Universidad de Salamanca / 요 Stud. his., H. ${ }^{a}$ mod., 41, n. 2 (2019), pp. 339-367 
condenas publicadas. Segundamente, cabría destacar que no todas las suplicaciones o apelaciones pedían la completa absolución de los condenados: como hemos dicho, en muchas ocasiones lo que estos buscaban era la disminución - la «moderación», usando sus propias palabras - de la condena. Finalmente, es necesario remarcar la estrecha relación que parece haber entre los porcentajes de suplicaciones y apelaciones aceptados, hecho que, a nuestro entender, confirmaría, el extremo que en buena medida el sistema de recursos establecido coincidiendo con las Cortes Catalanas de 1702 no fue otra cosa que la institucionalización de las suplicaciones presentadas durante el siglo XVII.

\subsection{Los decretos de ejecución de las sentencias. Potencialidad y limitaciones de una fuente documental}

La última tarea administrativa que los visitadores tenían que completar antes de hacer efectiva la ejecución de las sentencias no era otra que la publicación de los decretos de ejecución de las mismas. Estos documentos albergaban la decisión final del consistorio y, en el caso que se hubiera decidido aceptar las suplicaciones o alegaciones presentadas por los acusados, el decreto así lo especificaba. El potencial de esta fuente documental reside en el hecho que es un buen indicador del volumen y cumplimiento del trabajo desarrollado por la Visita. En este sentido, en base al análisis de los decretos de ejecución podemos dilucidar hasta qué punto los agentes fiscalizadores llevaron su cometido hasta las últimas consecuencias, puesto que conviene no olvidar que estos documentos eran la culminación del proceso administrativo. Sin embargo, la fuente presenta dos grandes limitaciones. En primer lugar, cabe destacar que el registro documental no es completo para todo el período estudiado, esto es, 1600-1714: antes bien, no se conservan los decretos de ejecución de las sentencias correspondientes a las siete primeras visitas, es decir, las comprendidas entre 1600 y 1623, así como tampoco conservamos aquellos relacionados con la inspección de 1629-1630. En segundo lugar, cabe destacar que la no conservación del decreto de ejecución de una sentencia no significa que aquella no fuera aplicada, es más, existen varios casos que así lo demuestran. Sirva de ejemplo de la Visita de 1629-1630, de la que no conservamos los decretos de ejecución, pero sabemos que algunos de los condenados fueron anotados en el Llibre de Vàlues del General en el que, como veremos más adelante, eran inscritos los condenados por la Visita después de que el racional de la Generalitat recibiera los decretos de ejecución de las sentencias ${ }^{29}$.

29. Las sentencias de la Visita de 1629-1630 se pueden consultar en ACA, Generalidad, Serie G, 8, 1. Por lo que respecta al Llibre de Vàlues del trienio de 1629-1632, ACA, Generalidad, Serie G, 85, 28.

Ediciones Universidad de Salamanca / @®@@ Stud. his., H. ${ }^{a}$ mod., 41, n. 2 (2019), pp. 339-367 
Hechas estas apreciaciones, si pasamos a analizar los datos recogidos en el cuadro $\mathrm{n}^{\circ} 6$, podemos observar que para el período comprendido entre 1600 y 1714 hemos podido recuperar 1.807 decretos de ejecución, lo que equivale al 53,65\% del total de sentencias publicadas (3.368). Este porcentaje relativamente discreto se puede explicar, en buena medida, en base a los pocos decretos de ejecución localizados durante los primeros cuarenta años del siglo XVII (350, un 23,50\% del total de sentencias publicadas) y siglo XVIII (109, un 48,23\% del total de sentencias publicadas), puesto que si nos fijamos en los años centrales y segunda mitad del seiscientos conservamos al entorno del $80 \%$ de los decretos. En el caso de los primeros años del siglo XVII, nuestra hipótesis para explicar la escasez de decretos de ejecución residiría en la más que probable pérdida de la documentación fruto de la dispersión documental típica de los registros de las sentencias de las primeras visitas. Tarea mucho más complicada nos parece, por el contrario, encontrar una explicación a la escasez de decretos de ejecución localizados para los primeros años del siglo XVIII. En este sentido, consideramos que la hipótesis más viable a la hora de explicar esta cuestión, residiría en la inestabilidad política sufrida por el Principado fruto del estallido de la Guerra de Sucesión Española (1701-1714).

Cuadro ${ }^{\circ}$ 6. Decretos de ejecución de las sentencias de la Visita, 1600-1714

\begin{tabular}{|c|c|c|}
\hline & Total Sentencias & D. Ejecución \\
\hline $1600-1640$ & 1.489 & $350(23,50 \%)$ \\
\hline $1640-1652$ & 361 & $313(86,70 \%)$ \\
\hline $1652-1659$ & 527 & $437(82,9 \%)$ \\
\hline $1659-1702$ & 765 & $598(78,16 \%)$ \\
\hline $1702-1714$ & 226 & $109(48,23 \%)$ \\
\hline $1600-1714$ & 3.368 & $1.807(53,65 \%)$ \\
\hline
\end{tabular}

Fuente: Elaboración propia a partir de ACA, Generalidad, Serie VG, 21, 26, 33, 37, 38, 212, 214, $58,70,79$ y Serie G, 8, 1-18.

2.3. ¿Un mecanismo infalible? El papel del racional y el exactor en la ejecución de las sentencias de la Visita del General

Hecho este breve repaso entorno al recorrido que tenían las sentencias de la Visita del General una vez estas eran dictadas por los visitadores, centrémonos ahora en el análisis del que fue su proceso de ejecución. En este sentido, el primer elemento que deberíamos dilucidar es quién o quienes se encargaban de ejecutar las sentencias promulgadas por los visitadores. La respuesta a esta cuestión es sencilla: 
los encargados de la ejecución de las sentencias promulgadas por los visitadores eran los propios visitadores o, en su defecto, aquellas personas «als qui són estades delegades y comeses per dits visitadors", como bien recogía un voto datado a 20 de abril de 1606 elaborado por un conjunto de asesores jurídicos reunidos por los visitadores $^{30}$. En definitiva, podían decidir si ellos mismos ejecutaban las sentencias en persona o delegaban esta tarea a terceros una vez redactados los decretos de ejecución. A pesar de que en algunas de las visitas realizadas durante la primera mitad del siglo XVII fueron los propios visitadores los que se encargaron personalmente de la ejecución de las sentencias - sirvan de ejemplo las de 1608 o $1626^{31}$ - lo cierto es que la tendencia fue delegar esta potestad a los diputados y oidores de cuentas, seguramente por motivos puramente prácticos - los visitadores finalizaban su actividad una vez transcurridos los nueve meses previstos por la legislación de la Visita y esto implicaba que no recibieran ninguna remuneración a partir de ese momento-. Esto, juntamente con el hecho que el procedimiento de exigir el pago de las penas pecuniarias era una tarea tradicionalmente (muy) lenta, seguramente favoreció que los visitadores considerasen que delegar esta tarea a los diputados era una forma eficiente de librarse de un buen quebradero de cabeza. Aunque conviene subrayar que estos últimos gozaban de unas herramientas para garantizar la ejecución de las sentencias que no estaban al alcance de los visitadores - por lo menos directamente-.

¿Cuáles eran las herramientas que permitían a los diputados actuar con mucha más contundencia para garantizar la correcta ejecución de las sentencias? Básicamente eran dos: 1- Los Capítulos del Redreç 46/1599 - por el que se determinaba que los deudores del General no podían participar en las insaculaciones destinadas a proveer los oficios de la Generalitat - y 49/1599 - que impedía participar a los deudores del General en los arrendamientos de los derechos de la Generalidad- . 2- La labor que realizaban dos oficiales de la Diputación conocidos como racional y exactor.

Analizaremos en primer lugar el papel que jugaron los Capítulos 46 y 49 del Redreç de 1599 arriba mencionados ${ }^{32}$. En la confección de ambos capítulos muy probablemente tuvo que ver la voluntad por parte de los estamentos reunidos en Cortes de solucionar el problema generado por la nómina cada vez más grande de deudores para con la hacienda del General, al mismo tiempo que se intentaba recuperar unos ingresos que parecían estancados. Mediante esta legislación se excluía de manera explícita al colectivo de deudores de los cargos más importantes y más lucrativos que la jurisdicción del General les podía ofrecer. El Capítulo 46 les privaba del acceso a las bolsas de diputados y oidores de cuentas, los cuales eran los

30. ACA, Generalidad, Serie VG, 240, f. 197v.

31. ACA, Generalidad, Serie VG, 34 y Serie G, 8, 2.

32. Se encuentran en Capitols per lo redrés, El capítulo 46 en las pp. 79-80 y el capítulo 49 en la p. 82.

Ediciones Universidad de Salamanca / అ@@ Stud. his., H. ${ }^{a}$ mod., 41, n. 2 (2019), pp. 339-367 
principales cargos políticos de la institución y verdadero objetivo de los miembros de la clase dirigente catalana. Similarmente, el Capítulo 49, excluía explícitamente de los arrendamientos de los derechos del General a aquellas personas que fueran deudoras para con su hacienda, así como también les impedía ejercer como avaladores de aquellos que se presentasen para arrendar un derecho.

Las consecuencias de este pequeño edificio legal son fáciles de vislumbrar: aquellas personas con poder político y económico que eran sentenciadas por la Visita e inscritas como deudores del General, hacían todo lo posible para pagar lo que debían, ya que de lo contrario perdían la oportunidad de obtener un cargo político, participar en los procesos de elección de los mismos o, simplemente, de formar parte en la (no siempre) lucrativa recaudación de los tributos de la Diputación ${ }^{33}$.

Para poner en marcha esta nueva normativa, los diputados gozaron de la ayuda de dos oficiales de la institución, el racional y el exactor. El oficio de racional de la Diputación había evolucionado desde su creación como escribano-contable auxiliar de los oidores de cuentas durante el siglo XV hasta convertirse en el principal empleado a nivel económico de la institución ${ }^{34}$. La característica más interesante de este cargo público desde el punto de vista de la ejecución de las sentencias de la Visita, es que por mandato del capítulo 3 de las Cortes de 1520 el racional tenía la obligación de elaborar un libro - conocido como Llibre de Vàlues - en el que posteriormente se íban a anotar todas aquellas personas que debían dinero a la Diputación ${ }^{35}$. El segundo de los oficiales que utilizaron los diputados para ejecutar eficazmente las sentencias hechas por los visitadores fue el exactor del General. La función principal de este cargo público desde su creación fue la de exhigir los deutes se deuran al General» «ab summa diligència» ${ }^{36}$. De que su acción fuera decidida dependía en buena medida el cobro de las cantidades establecidas por las sentencias de la Visita.

La actividad del racional y del exactor para con las sentencias de la Visita quedó plasmada en los Llibres de Vàlues de la Generalitat, el registro de deudores de la

33. Sobre los arrendamientos de los derechos del General, véase principalmente Pérez Latre, 2004: 109-114.

34. Isabel Sánchez de Movellán pormenoriza las principales características del racional durante los primeros años de existencia de este cargo, cuando el oficial recibía el nombre de «scrivà dels Oydors de comptes», (Sánchez de Movellán, 2004: 213-214). Sobre este oficial también remitimos a: Capitols resultants de las sentèntias, f. $38 \mathrm{v}-44 \mathrm{v}$.

35. Capitols resultants de las sentèntias, f. 39r. La legislación que obligaba el racional a anotar en el Llibre de Vàlues los deutores para con el General y las cantidades que estos debían fue el capítulo 10 de las Cortes de 1533, Capitols resultants de las sentèntias, f. 40v.

36. Capitols resultants de las sentèntias, ff. $67 \mathrm{v}-68 \mathrm{r}$. Todo parece indicar que esta característica quedó ya estipulada durante las Cortes celebradas en Tortosa el año 1420. Así mismo lo recoge Sánchez de Movellán, (2004: 234).

Ediciones Universidad de Salamanca / అ@@ Stud. his., H. ${ }^{a}$ mod., 41, n. 2 (2019), pp. 339-367 
institución. El análisis de los datos proporcionados por esta fuente nos permite, pues, constatar hasta qué punto las ejecuciones de las sentencias eran aplicadas hasta las últimas consecuencias. Sin embargo, en cuanto a esta fuente documental, cabría introducir dos precisiones metodológicas: en primer lugar, deberíamos ser conscientes del hecho que se trata de un registro que presenta un grado de conservación desigual. En este sentido, mientras que la mayoría de volúmenes de la segunda mitad del siglo XVII y principios del XVIII son perfectamente consultables, no podemos decir lo mismo por lo que a los volúmenes de las primeras seis décadas del seiscientos se refiere: entre 1600 y 1659 , de un total de dieciocho volúmenes, nueve no han podido consultarse ${ }^{37}$. En segundo lugar, es importante hacer hincapié en el hecho de que no todos los condenados por la Visita eran inscritos en los Llibres de Vàlues, bien porque los reos satisfacían la condena antes de ser anotados ${ }^{38}$, bien porque en algunas ocasiones el racional no fue del todo diligente en el desempeño de sus funciones ${ }^{39}$.

Hechas estas precisiones, pasemos a considerar ahora los datos extraídos de los Llibres de Vàlues. Contamos con cifras fiables para las visitas de 1600-1601, 1614-1615, 1623-1624, 1629-1630, 1656-1657, todas las inspecciones del período comprendido entre 1662 y 1699, 1704-1705, 1707-1708 y 1710-171140. Así, entre 1600 y 1714 un total de 412 sentencias terminaron con los involucrados anotados como deudores de la Generalitat en los diferentes volúmenes de los Llibres de Vâlues. De forma análoga, para los años analizados contamos con un total de 668 sentencias que terminaron en condena. De ello se infiere que para los períodos en los que tenemos la información necesaria - sentencias y deudores registrados en los Llibres de Vàlues-, el $62 \%$ de las condenas fueron efectivamente ejecutadas. Todavía cabe señalar que del total de 412 sentencias condenatorias anotadas en el

37. Concretamente, los volúmenes no disponibles son los siguientes: ACA, Generalidad, Serie G, 85: 24, 25, 27, 29, 30, 31, 32, 33, y 35.

38. Hay diversos ejemplos de ello: ACA, Generalidad, Serie VG, 26, f. 4222 (Visita de 1602-1603); ACA, Generalidad, Serie VG, 33, ff. 254r y 260r (Visita de 1605-1606); ACA, Generalidad, Serie VG, 214, camisa 159, f. 184r (Visita de 1611-1612); ACA, Generalidad, Serie VG, 58, ff. 228r-229v (Visita de 1614-1615).

39. Baste, como muestra, la sentencia de la querella n ${ }^{\circ} 42$ de la Visita de 1608-1609 contra Francesc Tarragó y Jeroni de Lana, racional y ex-racional, respectivamente, acusados de haber sido negligentes a la hora de anotar en el Llibre de Vâlues los nombres de los condenados por sentencias de la Visita. ACA, Generalidad, Serie VG, 37, ff. 25r-26r.

40. Los datos provienen del vaciado de los siguientes volúmenes de los Llibres de Vàlues: ACA, Generalidad, Serie G, 85, 22 (1600-1601); 23 (1614-1615); 26 (1623-1624); 28 (1629-1630); 34 (1656-1657); 36 (1662-1663); 37 (1665-1666); 38 (1668-1669); 39 (1671-1672); 40 (1674-1675); 41 (1677-1678); 42 (1680-1681); 43 (1683-1684); 44 y 45 (1686-1687); 44 (1689-1690); 45 (16921693); 46 (1695-1696); 47 (1698-1699); 48 (1704-1705); 49 (1707-1708); 50 (1710-1711). Entre paréntesis, la Visita a la que corresponden los datos.

Ediciones Universidad de Salamanca / 요 Stud. his., H. ${ }^{a}$ mod., 41, n. 2 (2019), pp. 339-367 
Llibre de Vàlues, en 216 ocasiones - el 53\% del total- los reos satisficieron la deuda antes de la finalización del trienio en el que la Visita había tenido lugar, en 38 ocasiones - el 9\% del total- lo hicieron parcialmente y, finalmente, en otras 158 ocasiones - el 38\% del total - no nos consta que pagaran lo adeudado.

Los datos ahora comentados nos permiten llegar a dos grandes conclusiones. En primer lugar, el hecho de que para aquellos casos en los que contamos con toda la documentación necesaria para reconstruir el procedimiento de ejecución de las sentencias, todo parece indicar que en la mayoría de los casos los visitadores ejercieron su cometido hasta las últimas consecuencias, esto es, decretar la ejecución de las sentencias. Además, hemos visto que la resolución de los agentes visitadores era obedecida diligentemente tanto por el racional, como por el exactor. Segundamente, resulta evidente que el hecho que el $62 \%$ de los anotados como deudores en los Llibres de Vàlues por sentencias de la Visita satisficiera o intentara satisfacer su deuda para con la hacienda de la Generalitat, es indicativo del correcto funcionamiento del entramado legislativo aprobado por las Cortes Catalanas de 1599 -Capítulos del Redreç 46 y 49/1599-.

\section{CONCLUSIONES}

I. La introducción de este estudio la hemos dedicado a hacer un breve repaso historiográfico en relación a los trabajos dedicados a los sistemas de fiscalización de la Monarquía Hispánica de los Austrias, haciendo hincapié en una tesis muy difundida, esta es, la de la poca efectividad (cuando no «inutilidad») de Visitas, Juicios de Residencia y Pesquisas, pero, a nuestro entender, un tanto infundada. Si bien no pocos autores se han pronunciado en este sentido, cierto es que a día de hoy no existe ningún trabajo sistemático entorno a los outputs generados por estos sistemas de fiscalización, es decir, sus sentencias y su proceso de ejecución.

II. En la primera parte de nuestro trabajo, hemos planteado un estudio cuantitativo de las sentencias de la Visita del General de Catalunya, es decir, el sistema de fiscalización de los oficiales públicos de la Generalitat de Catalunya durante la época moderna. Este análisis nos ha permitido determinar el volumen total de sentencias producidas por el ente fiscalizador entre 1600 y 1714 (3.368), precisar cuántas de ellas terminaron en condena (1.417) y cuántas en absolución (1.680), evidenciar que los oficiales «forans» coparon la mayoría de las sentencias o que diputados y oidores de cuentas, por un lado, y tablajeros por otro lado fueron los oficiales más perseguidos por la Visita. Como hemos podido observar, cuatro son las hipótesis que nos permiten explicar estas diferencias en cuanto a la oficialidad: la facilidad u la dificultad de acceso a la legislación vigente por parte de los oficiales; una mayor concreción de las disfunciones de tipo administrativo en el caso de los oficiales «forans»; el uso de operadores jurídicos de menor calidad en el caso de los

Ediciones Universidad de Salamanca / 요 Stud. his., H. ${ }^{a}$ mod., 41, n. 2 (2019), pp. 339-367 
oficiales «forans»; y, finalmente, el hecho que los oficios de la colecta de Barcelona estuviesen copados tradicionalmente por miembros de la clase dirigente barcelonesa, los cuales contaban con mayores cuotas de influencia dentro del entramado institucional del Principado.

III. La segunda parte de nuestra investigación se ha centrado en exponer el funcionamiento del sistema de ejecuciones de las sentencias de la Visita del General de Catalunya, acordado en el marco de las Cortes Catalanas de 1599. Así, hemos pormenorizado el sendero que tomaban las sentencias de la Visita una vez eran publicadas, esto es: suplicación/apelación, decreto de ejecución y ejecución efectiva. Posteriormente, el análisis del cometido tanto del racional, como del exactor nos ha permitido constatar que en aquellos casos para los que conservamos toda la documentación para reconstruir el proceso de ejecución de las sentencias, más del $60 \%$ de las sentencias promulgadas por la institución fiscalizadora eran efectivamente ejecutadas. Más aún, ello nos ha permitido constatar que el $62 \%$ de las personas ejecutadas por sentencias de la Visita bien pagaron, bien intentaron pagar lo adeudado por las condenas impuestas, lo que nos demostraría hasta que punto el sistema habría gozado de aceptación.

IV. Los datos aportados a partir del análisis, tanto de las sentencias de la Visita como de las ejecuciones de las mismas, demuestran bien a las claras la existencia de unos procedimientos perfectamente diseñados e implementados con el objetivo de hacer cumplir los dictámenes pronunciados por los visitadores. En este sentido, a diferencia de lo apuntado mayoritariamente por la historiografía especializada, hemos podido comprobar que en aquellos casos en los que disponemos de datos concretos seis de cada diez condenas eran efectivamente ejecutadas. Es por ello que consideramos que deberíamos empezar a poner en duda las tesis que tradicionalmente se habrían referido a los sistemas de fiscalización de la Monarquía Hispánica de los Austrias como mecanismos «inútiles» e «ineficaces».

V. No quisiéramos concluir este trabajo sin remarcar dos cuestiones fundamentales que, por cuestiones de enfoque y espacio, deberían ser discutidas profusamente en futuros estudios.

En primer lugar, la del análisis comparativo de los sistemas de producción y ejecución de las sentencias inherentes a los distintos mecanismos de fiscalización de los oficiales públicos a lo largo y ancho de los territorios de la Monarquía Hispánica de los Austrias. Para ello, sería necesario que se dejaran de lado enfoques demasiado descriptivos - denunciado recientemente en un estado de la cuestión (Andújar Castillo, Feros y Ponce Leiva, 2017: 305) - sobre casos muy concretos, para proceder a análisis sistemáticos sobre visitas, juicios de residencia y pesquisas. Sirva de ejemplo el caso mismo del Principado de Cataluña: mientras que en el caso 
de la Visita del General de Catalunya hemos podido comprobar el éxito relativo del sistema de ejecución de las sentencias, el análisis de los procesos y sentencias de la Visita de los oficiales reales en Cataluña de 1635 indica un panorama diferente, protagonizado por un elevado índice de absoluciones fruto del poco interés del monarca en indagar en procesos en los que la acusación cuestionaba su jurisdicción. ${ }^{41}$ Los motivos de esta disimilitud entre uno y otro sistemas de fiscalización residiría, a nuestro entender, en la idea fundacional misma de ambas instituciones: así, mientras que la Visita del General tendría sus orígenes en el control ejercido por los estamentos reunidos en las Cortes Catalanas bajomedievales (Torra i Prat, 2019) y perseguiría la conservación de la Generalitat entendida como institución que representaría los intereses de la comunidad política del Principado - existía, por lo tanto, un pacto entre los estamentos a la hora de autoimponerse unos límites en aras de preservar la Generalitat-, la Visita de los oficiales reales habría nacido en las Cortes de Barcelona de 1599 sin un acuerdo claro respecto a su naturaleza: por un lado, el monarca la habría concebido como un mecanismo para informarse del funcionamiento de las instituciones reales y el comportamiento de sus oficiales; por otro lado, los estamentos la habrían visto como un mecanismo para corregir los agravios cometidos, precisamente, por los oficiales del monarca (Serra i Puig, 2003: 26).

En segundo lugar, la de un análisis cualitativo de las sentencias dictadas por la Visita del General centrado en las acusaciones con el objetivo de constatar cuáles fueron los cargos más recurrentes y, muy especialmente, dilucidar hasta qué punto una determinada acusación - por ejemplo, la de baratería - condujo (u no) de forma recurrente a una condena. Ambos casos exceden, y mucho, el espacio de este trabajo: En primer lugar, porque las acusaciones vertidas por los visitadores de la Generalitat citadas en las sentencias ascendieron a un total de 6.597 y sobrepasan las principales categorías delictivas previstas por el derecho común en juicios de Visita - los supuestos de dolo, fraude, baratería o crimen corruptionis -, suponiendo su clasificación y explicación un reto nada desdeñable (Torra i Prat, 2018: 224-235); segundamente, y por lo que a dilucidar cuáles acusaciones condujeron a una condena, resulta una tarea difícilmente realizable solamente a partir de las sentencias, puesto que en muchas ocasiones estas no lo especifican, especialmente en aquellos casos en que una querella contemplaba diversas acusaciones. Es por ello que un estudio como este debería ejecutarse analizando uno por uno todos los procesos de la Visita del General entre 1600 y 1714: esperamos poderlo realizar en un futuro.

41. Los procesos de la Visita Real de 1635 en: ACA, Generalidad, Serie RV: 50, 4-12; 51, 13-19; 52, 20-23; 53, 24-27; 54, 28-35; 55, 36-40; 56, 41-49; 57, 50-53; 58, 54-58; 59, 59-65; 60, $66-75 ; 61,76-84 ; 62,85-94 ; 63,96-103 ; 64,104-108 ; 65,109-116$.

Ediciones Universidad de Salamanca / @®@@ Stud. his., H. ${ }^{a}$ mod., 41, n. 2 (2019), pp. 339-367 
RICARD TORRA-PRAT

EL QUID DE LA CUESTIÓN. SOBRE SENTENCIAS DE VISITA Y SU EJECUCIÓN

EL CASO DE LA VISITA DEL GENERAL DE CATALUNYA, 1599-1711

\section{BIBLIOGRAFÍA}

ALBAREDA, J. (2010). La Guerra de Sucesión de España (1700-1714). Barcelona: Crítica. AMELANG, J. S. (1986). La formación de una clase dirigente: Barcelona 1490-1714. Barcelona: Ariel.

ANDÚJAR CASTILlO, F., FEROS, A. y PONCE LEIVA, P. (2017). Corrupción y mecanismos de control en la Monarquía Hispánica: una revisión crítica. Tiempos Modernos: Revista electrónica de historia moderna, 35, 284-311.

CAPDEFERRO I PLA, J. y SERRA I PUIG, E. (2015). El Tribunal de Contrafaccions de Catalunya i la seva activitat (1702-1713). Barcelona: Parlament de Catalunya Generalitat de Catalunya.

COLLANTES DE TERÁN DE LA HERA, M. J. (1998). El juicio de residencia en Castilla a través de la doctrina jurídica de la edad moderna. Historia. Instituciones. Documentos., 25, 151-184.

Cort General de Barcelona (1705-1706). Procés familiar del braç militar. (2016). Barcelona: Parlament de Catalunya - Generalitat de Catalunya.

Dietaris de la Generalitat de Catalunya, vol. II (2002). Barcelona: Generalitat de Catalunya.

GARRIGA ACOSTA, C. (1991). Control y disciplina de los oficiales públicos en Castilla: la «visita» del ordenamiento de Toledo (1480). Anuario de Historia del Derecho Español, 61, 215-390.

GÓMEZ GONZÁLEZ, I. (2016). Entre la corrupción y la venalidad: don Pedro Valle de la Cerda y la visita al Consejo de Hacienda de 1643. En Andújar Castillo, F. y Ponce Leiva, P. (Coords.). Mérito, venalidad y corrupción en España y América, siglos XVII y XVIII. Valencia: Albatros, 235-249.

GÓMEZ GONZÁLEZ, I. (2017). El control de la corrupción en los tribunales castellanos durante el siglo XVII: ¿Quimera o realidad?. Tiempos Modernos: Revista electrónica de historia moderna, 35, 312-336.

GONZÁLEZ ALONSO, B. (1978). El juicio de residencia en Castilla. Anuario de Historia del Derecho Español, 48, 193-247.

GONZÁLEZ PEINADO, C. (2010) El inicio del juicio de residencia don Alonso de Granada Venegas (Ocaña, Toledo, 1597): algunas notas sobre su procedimiento. Espacio, tiempo y forma. Serie IV, Historia moderna, 23, 41-57.

HEREDIA LÓPEZ, A. J. (2017). La oposición al control de los servidores a la visita de Juan de Gongora a la Casa de la Contratación y Consulado de Sevilla en 1642. En Gil Martínez, F. y Villarreal Brasca, A. (Eds.). Estudios sobre la corrupción en España y América (siglos XVI-XVIII). Almería: Edual, 189-207.

HERZOG, T. (2000). Ritos de control, prácticas de negociación: Pesquisas, visitas y residencias y las relaciones entre Quito y Madrid (1650-1750). Madrid: Fundación Hernando de Larramendi.

FERRER I MALLOL, M. T. (Dir.) (2011). Història de la Generalitat de Catalunya. Dels orígens medievals a l'actualitat, 650 anys. Barcelona: Institut d'Estudis Catalans Generalitat de Catalunya.

Ediciones Universidad de Salamanca / @®@@ Stud. his., H. ${ }^{a}$ mod., 41, n. 2 (2019), pp. 339-367 
JIMÉNEZ JIMÉNEZ, I. (2015). Una herramienta inútil. Juicios de Residencia y Visitas en la Audiencia de Lima a finales del siglo XVII. Temas Americanistas, 35, 60-87.

LLINÁS ALMADANA, P. (1990). La Visita del General: el procedimiento de control de los funcionarios dependientes de la Diputació del General de Catalunya (1653-1701). Pedralbes: revista d'bistòria moderna, 10, 177-192.

LÓPEZ DE LA PLAZA, G. (2008). Els arxius de la Diputació del General de Catalunya. Un recorregut tècnic pels estils de custòdia i descripció d'un fons històric. Butlletí de la Reial Acadèmica de Bones Lletres de Barcelona, 51, 39-74.

MACRI, G. (2008). Visitas Generales e sistemi de controllo regio nel sistema imperiale spagnolo: un bilancio storiografico. Mediterranea. Ricerche storiche, 13, 385-400.

MALAPRADE, S. (2017). Crédito y corrupción. La visita al Consejo de Hacienda de 1643. Tiempos Modernos: Revista electrónica de historia moderna, 35, 363-387.

MARTÍ FRAGA, E. (2009). La classe dirigent catalana. Els membres de la Conferència dels Tres Comuns i del Braç Militar (1697-1714). Barcelona: Fundació Noguera.

OLEART, O. (1993). La creació del dret: els anomenats capitols del redreç del General de Catalunya. Pedralbes: Revista d'Història Moderna, 13-1, 245-258.

PÉREZ LATRE, M. (2004). La Generalitat de Catalunya en temps de Felip II. Política, administració i territori. Afers: Catarroja.

PEYTAVIN, M. (2003). Visite et gouvernement dans le royaume de Naples (XVIe-XVIIe siècles). Madrid: Casa de Velázquez.

RIVERO RODRÍGUEZ, M. (1998). Buen gobierno y ejemplaridad: la Visita del Consejo de Italia. En Martínez Millán, J. (Dir.). Felipe II (1527-1598): Europa y la monarquía católica. Congreso internacional «Felipe II (1598-1998), Europa dividida, la monarquia católica de Felipe II (Universidad Autónoma de Madrid, 20-23 abril 1998), vol. I, tomo II. Madrid: Parteluz, 705-730.

ROVITO, P. L. (1981). Respublica dei togati: giuristi e societa’ nella Napoli del Seicento. Nápoles: Jovene.

SÁNCHEZ BELLA, I. (1980). Eficacia de la Visita en Indias. Anuario de Historia del Derecho Español, 50, 383-412.

SÁNCHEZ DE MOVELLÁN TORENT, I. (2004). La Diputació del General de Catalunya (1413-1479). Institut d'Estudis Catalans: Barcelona.

SERRA I PUIG, E. (2003). Les Corts catalanes, una bona font d'informació històrica: discurs de recepció d'Eva Serra i Puig com a membre numerària de la Secció Històrico-Arqueològica, llegit el dia 27 de novembre de 2003. Barcelona: Institut d'Estudis Catalans.

SERRA I PUIG, E. (2011). Territori i inspecció fiscal: la Visita del General del 1600. En Dantí, J. (Coord.). Les xarxes urbanes a la Catalunya dels segles XVI i XVII. Barcelona: Rafael Dalmau, 165-284.

TORRA I PRAT, R. (2014). Mites o realitats? Sobre el paper de les Corts Catalanes altmodernes com a generadores de dret. El cas de la Visita del General. Estudis. Revista de Historia Moderna, 40, 115-132.

Ediciones Universidad de Salamanca / @®@ Stud. his., H. ${ }^{a}$ mod., 41, n. 2 (2019), pp. 339-367 
TORRA I PRAT, R. (2015). La fiscalización de la actividad de los oficiales de la Generalitat de Cataluña en la época moderna. La Visita del General de Cataluña y su funcionamiento. Cuadernos de Historia del Derecho, 22, 295-317.

TORRA PRAT, R. (2016). El juego de las instituciones. Políticas de la Visita del General de Catalunya durante la primera mitad del siglo XVII. Tiempos Modernos: Revista electrónica de historia moderna, 32, 249-279.

TORRA I PRAT, R. (2018). La Visita del General de Catalunya: la institució i el seu encaix en el sistema institucional català d'època moderna (segles XV-XVIII), tesis doctoral. Universitat Autònoma de Barcelona.

TORRA I PRAT, R. (2019). Visitar, estudiar, discutir i legislar. L'acció fiscalitzadora de les Corts Catalanes durant el segle XVI. En Serra, S., Ripoll, E. (Eds.) El Parlamentarisme en perspectiva histórica. Parlaments multinivell. Vol. II. Mallorca: Parlament de les Illes Balears - IEA, 1239-1256.

Ediciones Universidad de Salamanca / @®@ Stud. his., H. ${ }^{a}$ mod., 41, n. 2 (2019), pp. 339-367 